\title{
Correction to: Suicide ideation and attempts among people with epilepsy in Addis Ababa, Ethiopia
}

Kelelemua Haile ${ }^{1}$, Tadesse Awoke ${ }^{2}$, Getinet Ayano ${ }^{1}$, Minale Tareke ${ }^{3 *}$, Andargie Abate ${ }^{3}$ and Mulugeta Nega ${ }^{4}$

\section{Correction to: Ann Gen Psychiatry (2018) 17:4 https://doi.org/10.1186/s12991-018-0174-6}

After publication of the article [1], it has been brought to our attention that an author's name was spelt incorrectly in the original published article. Getinet Ayano was previously spelt "Getnet Ayano". This has now been corrected in the revised version of the article.

\section{Author details}

${ }^{1}$ Department of Psychiatry, Amanuel Mental Specialized Hospital, Addis Ababa, Ethiopia. ${ }^{2}$ Department of Epidemiology and Biostatistics, University of Gondar, Gondar, Ethiopia. ${ }^{3}$ College of Medicine and Health Science, Bahir Dar University, Bahir Dar, Ethiopia. ${ }^{4}$ College of Medicine and Health Science, Haramaya University, Harer, Ethiopia.

The original article can be found online at https://doi.org/10.1186/ s12991-018-0174-6.

\section{Publisher's Note}

Springer Nature remains neutral with regard to jurisdictional claims in published maps and institutional affiliations.

Received: 24 February 2018 Accepted: 24 February 2018

Published online: 07 March 2018

\section{Reference}

1. Haile K, Awoke T, Ayano G, Tareke M, Abate A, Nega M. Suicide ideation and attempts among people with epilepsy in Addis Ababa, Ethiopia. Ann Gen Psychiatry. 2018;17:4. https://doi.org/10.1186/s12991-018-0174-6.

Full list of author information is available at the end of the article 